\title{
Influence of graft quality on donor and recipient outcomes in living donor kidney transplantation
}

\author{
Ioanna G. Panagiotopoulou¹, Yining Chen², Vasilis Kosmoliaptsis ${ }^{1}$, Victoria Bardsley³, \\ Gavin J. Pettigrew ${ }^{1}$, J Andrew Bradley ${ }^{1}$, Kourosh Saeb- Parsy ${ }^{1}$
}

1 Department of Surgery, University of Cambridge, Cambridge, CB2 0QQ; 2 Statistical Laboratory, Centre for Mathematical Sciences, University of Cambridge, Cambridge, CB3 OWB; 3 Department of Pathology, Cambridge University Hospitals NHS Trust, Cambridge, CB2 0QQ

\section{BACKGROUND}

Living kidney donation (LKD) programmes are increasingly developed worldwide as there is a limited supply of organs from deceased donors.

LKD programmes are associated with better short and long-term graft survival and function compared with transplants from donation after brainstem death (DBD) and circulatory death $(\mathrm{DCD})^{1,2}$.

We investigated factors that may account for the superior donor and recipient outcomes after LKD transplantation, including donor kidney quality as measured by time-zero biopsies $^{3}$

\section{METHODS}

318 LKD transplants between January 2000 and March 2012 were examined in a prospectively maintained database.

Multivariate and survival analyses were performed to identify variables predictive of donor or recipient glomerular filtration rate (GFR) and graft survival.

Outcomes were also compared between 102 LKD 97 DBD and 191 DCD recipients who had contemporary time-zero biopsy scores.

\section{RESULTS- DONOR GFR}

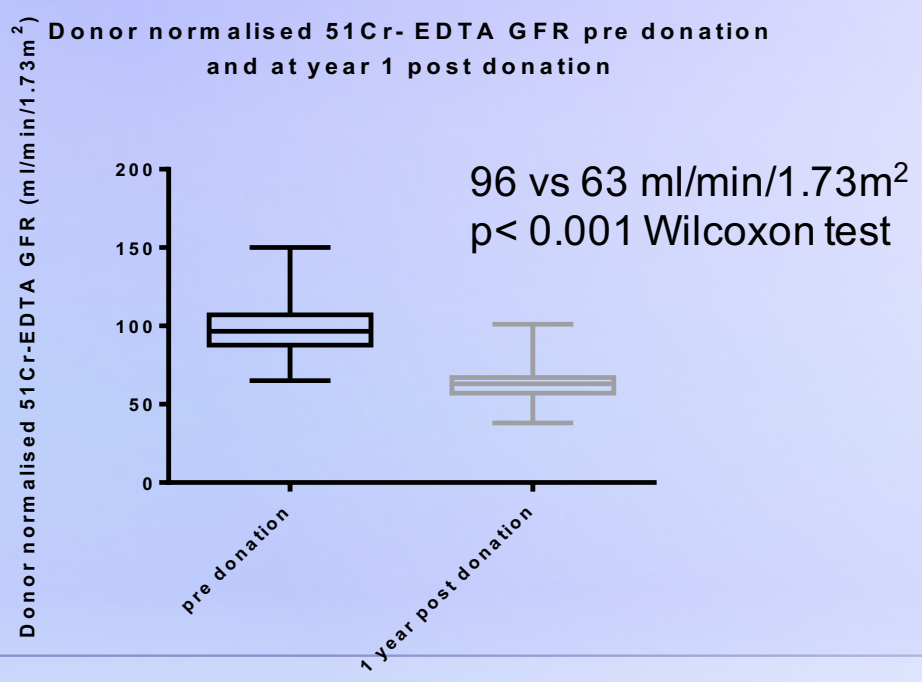

Donor age and BMI were predictive of measured donor GFR change at 1 year post donation

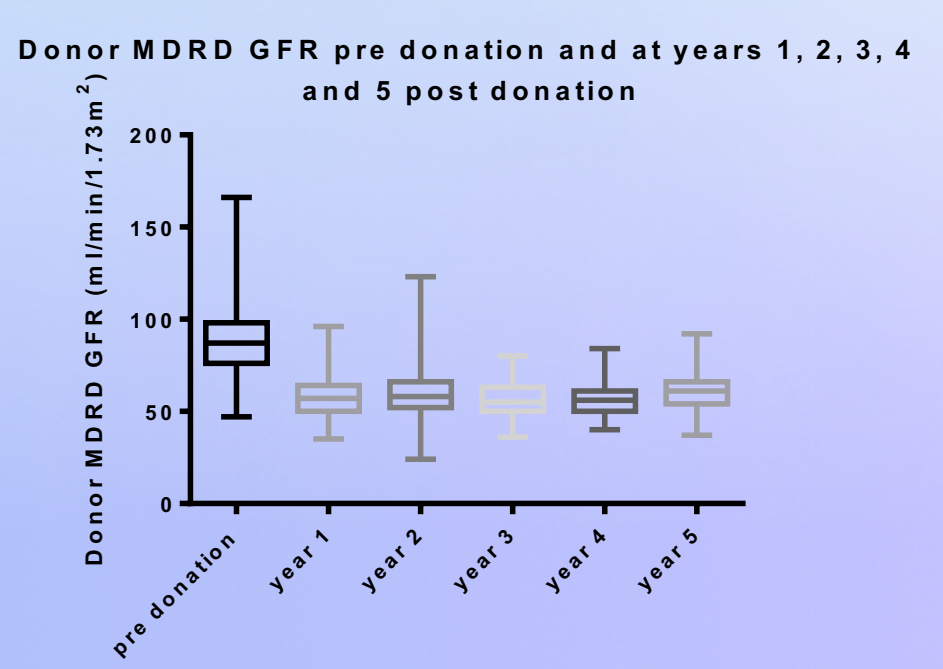

Donor age was the only significant predictive factor for donor estimated GFR (eGFR) at 5 years post donation on linear regression analysis

\section{RESULTS- RECIPIENT GFR}

\begin{tabular}{|l|l|l|l|l|}
\hline & variables & Coefficient & $\begin{array}{l}\text { Standard } \\
\text { Error }\end{array}$ & p value \\
\hline $\begin{array}{l}\text { Recipient year 1 } \\
\text { log-eGFR }\end{array}$ & Donor age & -0.011 & 0.001 & $<0.001$ \\
\cline { 2 - 5 } & Donor gender & -0.067 & 0.031 & 0.029 \\
\cline { 2 - 5 } & Recipient age & -0.003 & 0.001 & 0.021 \\
\hline $\begin{array}{l}\text { Recipient year 5 } \\
\text { log-eGFR }\end{array}$ & Donor age & -0.014 & 0.003 & $<0.001$ \\
\hline
\end{tabular}

Table 1: Multivariate regression analyses predicting recipient logeGFR at 1 and 5 years post transplantation. The independent variables were: donor age, donor gender, recipient age, recipient

gender, pre donation radioisotope GFR and biopsy scores.

A 10 year increase in donor age lead to a $10 \%$ and $13 \%$ decrease in recipient eGFR at years 1 and 5 respectively.

A 10-year increase in recipient age resulted in a 3\% decrease in recipient eGFR at 1 year post transplantation.

Kidneys from female donors are associated with a $6 \%$ lower recipient eGFR at year 1 post transplantation.

\section{RESULTS- GRAFT SURVIVAL}

No statistically significant factors predicting LKD graft survival were identified in Cox regression analysis.

\section{Death-censored LKD graft survival}

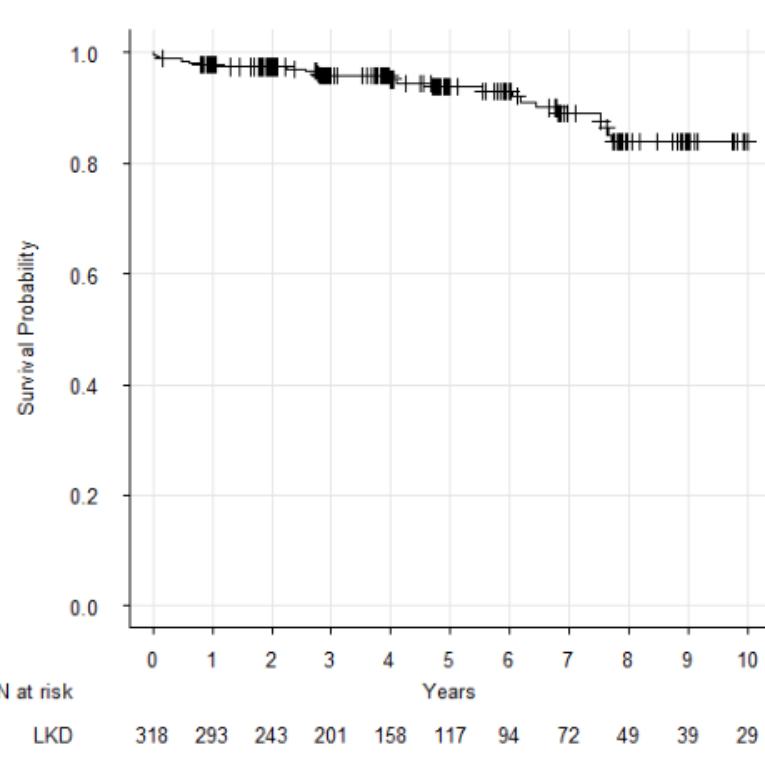

Influence of time zero biopsy on LKD graft survival
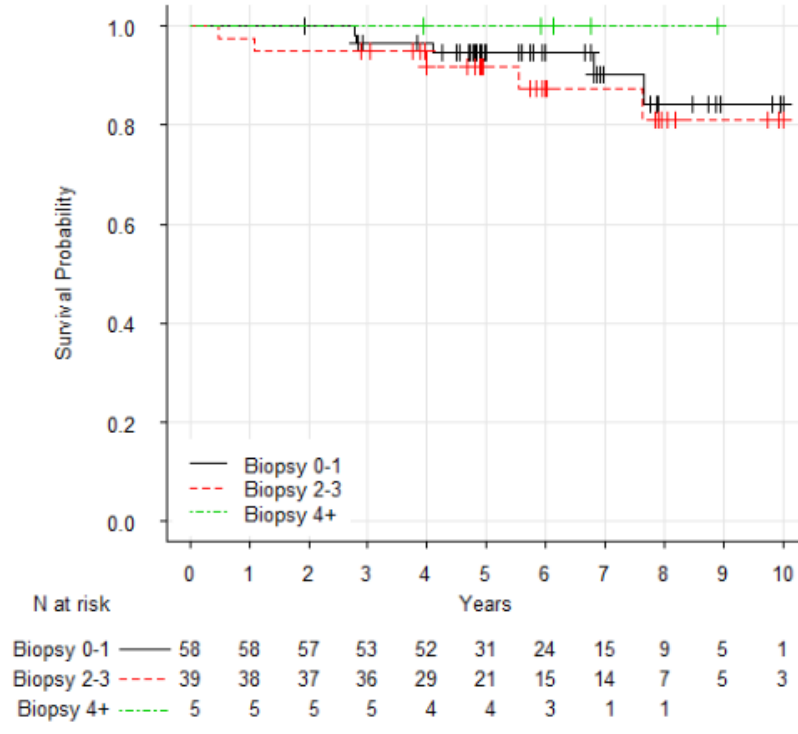

Graft survival in living kidney transplants was not affected by biopsy score (Log-rank Mantel-Cox test: $p=0.643$ )

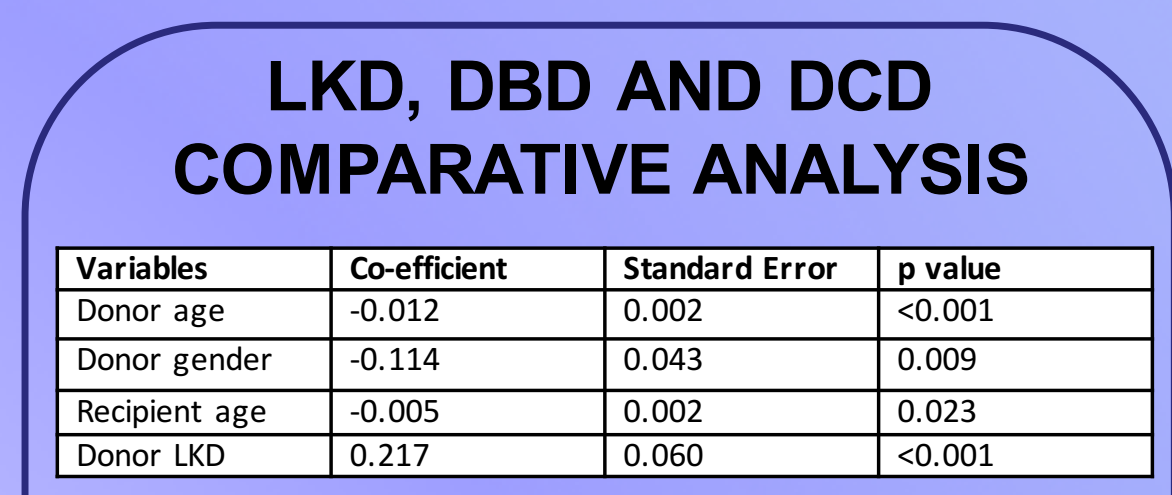

Table 2: Multivariate regression analyses predicting recipient logeGFR at 1 year post transplantation. The independent variables were: donor age and gender, recipientage and gender mismatch levels, biopsy scores (0-3 due to limited numbers of LKD biopsy scores of 4 and 5 , donor type with DBD taken as base. Cold ischaemia time was not included as it was surrogate marker for LKD.

Donor type was a significant predictor of recipient GFR at year 1 post transplantation, with LKD transplants resulting in a $24 \%$ higher recipient GFR compared with DBD grafts.

\begin{tabular}{|l|l|l|l|}
\hline variables & Coefficient & Standard Error & P value \\
\hline LKD donor & -1.251 & 0.580 & 0.030 \\
\hline
\end{tabular}

Table 3: A Cox multivariate analys is was performed to identify risk factors for graft survival. The independent variables included in the model were: donor type (DBD as base), donor age and gender recipient age and gender, biopsy score $(0-3)$ and mismatch level.

The risk of graft loss of LKD transplants was approximately $25 \%$ that of $\mathrm{DBD}$.

Of note, time-zero biopsy scores were not significant in predicting graft survival of LKD, DBD and DCD kidneys with time-zero biopsy scores $0-3$.

\section{CONCLUSIONS}

Donor age is the most significant factor affecting LKD donor and recipient eGFR at 1 and 5 years post donation or transplantation.

After the initial fall, donor eGFR remains stable at 5 years.

Donor kidney biopsy score is not predictive of donor eGFR.

The superior performance of LKD transplants compared to DCD and DBD kidney transplantation is not accounted for by variables such as donor age and kidney biopsy score.

\section{REFERENCES}

1. Harriharan S, Johnson CP, Bresnahan BA, Taranto SE Mclntosh MJ, Stablein D. Improved graft survival after rena transplantation in the United States. NEJM 2000; 342: 605612.

2. Terasaki PI, Cecka JM, Gjertson DW, Takemoto S. High survival rates of kidney transplants from spousal and living unrelated donors. NEJM 1995; 333: 333- 336.

3. Remuzzi G, Grinyo J, Ruggenenti P, Beatini M, Cole EH, Milford EL, Brenner BM. Early experience with dual kidney transplantation in adults using expanded donor criteria Double Kidney Transplant Group (DKG). J Am Soc Nephrol 1999; 10: 2591-2598. 